\title{
Superficial treatment by anodization in order to obtain titanium oxide nanotubes applicable in implantology
}

\author{
Sandra Raquel Kunst ${ }^{1}$, Thaís Francine Graef ${ }^{2}$, Luã Tainachi Mueller ${ }^{2}$, \\ Fernando Dal Pont Morisso ${ }^{2}$, Carlos Leonardo Pandolfo Carone ${ }^{2}$, \\ Luciane Taís Fuhr $^{2}$, Cláudia Trindade Oliveira ${ }^{2}$, Jane Zoppas Ferreira ${ }^{1}$
}

\author{
${ }^{1}$ LACOR, Universidade Federal do Rio Grande do Sul - UFRGS, Avenida Bento Gonçalves, 9500, Porto Alegre, RS, \\ Brasil. \\ ${ }^{2}$ ICCT, Universidade Feevale, RS-239, 2755, Novo Hamburgo, RS, Brasil. \\ e-mail: cto@feevale.br, tessaro.sandra@gmail.com,tfg@outlook.com, panzermueller@gmail.com, morisso@feevale.br, \\ carloscarone@feevale.br, luciane.fuhr@gmail.com, cto@feevale.br, jane.zoppas@ufrgs.br
}

\begin{abstract}
Titanium and its alloys are the most popular metals applied on end osseous implants manufacturing. Commercially pure titanium (Ti c.p.) has been successfully used as a biomaterial because of its mechanical and chemical properties, excellent corrosion resistance and biocompatibility. In order to improve and accelerate the osseointegration process after implantation, superficial treatments are performed aiming properties that stimulate the growth of the newly-formed bone. In this work, self organized titanium dioxide $\left(\mathrm{TiO}_{2}\right)$ nanotubes were obtained by anodic oxidation on Ti c.p. (grade 2). Also, it has been shown that the process is industrially reproducible for this purpose. As parameters for the anodizing process, it was concluded that the optimal electrolyte was $\mathrm{H}_{3} \mathrm{PO}_{4}$ solution $+0.15 \% \mathrm{HF}$ under potentiostatic mode for 30 minutes. Potentials of 1 , $5,10,15$ and $20 \mathrm{~V}$ were tested in order to verify the best conditions to obtain nanotubes. In this case, potential was set at $10 \mathrm{~V}$. The morphology of the samples was characterized by Scanning Electron Microscopy (SEM), Scanning Electron Microscopy with Field Emission (SEM-FEG) and Atomic Force Microscopy (AFM). The results showed the nanotubes formation throughout the titanium samples surface. In accordance to the obtained roughness, it was observed that the formed nanotubes film is thin, however, the literature indicates that the film thickness is not relevant on the performance of nanostructures as optimizers of the osseointegration process, unlike the nanotubes morphology and diameter. In the wettability analysis, the nanotubes behaved as hydrophilic. Therefore, it is possible to obtain $\mathrm{TiO}_{2}$ nanotubes for using in implants by a superficial treatment, allowing a better osseointegration quality.
\end{abstract}

Keywords: Titanium, Nanotubes, Anodization, Implants, Osseointegration.

\section{INTRODUCTION}

In the dental field, several researches are carried out aiming superficial treatments that assign some properties to the materials, such as high corrosion resistance, negligible ions release from the toxicological point of view, suitable mechanical properties for their final application and response of the surrounding biological system [1]. Among these properties, the most significant is the biological system response, because it is responsible for the osseointegration, in other words, by direct anchoring through the bone tissue formation around it $[2,3]$. In this context, for a biomaterial to be considered efficient as to the osseointegration process, it must induce a fast and controlled tissues healing and the material surface must present an interaction with the organism, promoting chemical and physical signals that guide the cells differentiation and grouping, giving its biofunctionality $[4,5]$. So, a medical device, besides fulfill its intended function, must interact with the host body without causing undesirable local or systemic effects, thus, biomaterials must have certain essential requirements as biocompatibility, biofunctionality, degradation resistance against body fluids and bioadhesiveness (biological adhesion) $[2,6,7]$.

In these circumstances, studies have confirmed that commercially pure titanium dental implants, after the superficial treatment, present a good performance for aesthetic and functional rehabilitation due to its mechanical and chemical properties, excellent corrosion resistance and biocompatibility [1, 8-11]. However, titanium, as a bioinert material, does not promote cell growth and, consequently, osseointegration. Several superficial treatments as sandblasting, acid attack, anodic oxidation, coating with a layer of biocompatible materials, ion implantation techniques and plasma vapor deposition techniques have been used on titanium with the aim of improving its superficial properties for optimization of the osseointegration process. The development and the use of these techniques are based on the theory that the increase in bone/implant contact 
can be attained by changing the topography or by increasing the implant superficial roughness [12, 13].

Some of these techniques are currently used in implants traded on the world market. From them, the electrochemical process of anodization allows to obtain a relatively thin oxides layer, which is denser than the oxide films naturally formed in the atmosphere. In the case of titanium, this layer has been used to favor the apatites nucleation, which are responsible for turning the titanium surface into nanotubular structures with diameters smaller than $100 \mathrm{~nm}$, benefiting the osseointegration process [14-17]. Moreover, by simply adjusting the process parameters such as electrolyte composition and applied current density and potential, it can be seen that the chemical and topographical properties of the surface can be precisely modulated, allowing complete control of the surface characteristics $[14,18]$.

Thus, to accelerate the osseointegration process, the implants must induce positive responses to surrounding tissue cells, as well as ensure cell adhesion. Therefore, in order to increase the surface area and the quality of the adhesion of the bone-implant interface, surface modification processes have been proposed based on the principle that a better and faster osseointegration can be achieved by the topographic modification of the implant [19-21].

The objective of this study was to determine the best electrolyte (reagents and concentrations) to obtain self-organized nanotubes, with homogeneous dimensions and distribution along the surface, besides to characterize the formed surfaces to qualify the influence of the potential difference applied during the anodization process in the growth of the nanotubes, in dimensional terms, and to analyze the formed titanium dioxide films on the surface to define its morphology, dimension, roughness, wettability and corrosion resistance.

\section{MATERIALS AND METHODS}

\subsection{Materials}

For the anodizing process, milled titanium c.p. grade 2 panels (ASTM F67) with $20 \mathrm{~mm}$ in diameter and 1 $\mathrm{mm}$ thick were used, supplied by Sandinox. The panels were polished and pickled a $\mathrm{HF}: \mathrm{HNO}_{3}$ solution. The samples were observed under optical microscope to verify the final appearance after the superficial preparation and visualization of the grain boundary.

The substrate was fixed by direct contact on a $0.3 \mathrm{~mm}$ thick Ti c.p. strip, that was connected as the anode into the positive pole of a voltage source, and in the negative pole was connected a platinum wire as counter electrode in the process.

As electrolyte, an aqueous solution containing $1 \mathrm{M} \mathrm{H}_{3} \mathrm{PO}_{4}$ (Merck) and additions of $\mathrm{HF}$ between $0.10 \%$ and $0.40 \% \mathrm{w} / \mathrm{v}$ (Química Moderna ${ }^{\circledR}$ ) was used. $\mathrm{H}_{3} \mathrm{PO}_{4}$ was employed to allow the ionization of three $\mathrm{H}+$ cations and to present residual phosphate ions, which can react with calcium titanates present in the body fluid, forming a calcium phosphate, which can turn into apatite, chemically bonding the implant to the living tissue $[9,22]$.

The anodization process was done using a voltage source $(0-300 \mathrm{~V}, 0-0.5 \mathrm{~A})$, with remote control by computer. The acquisition of applied voltage and current data were controlled by a software throughout the process (Figure 1). 


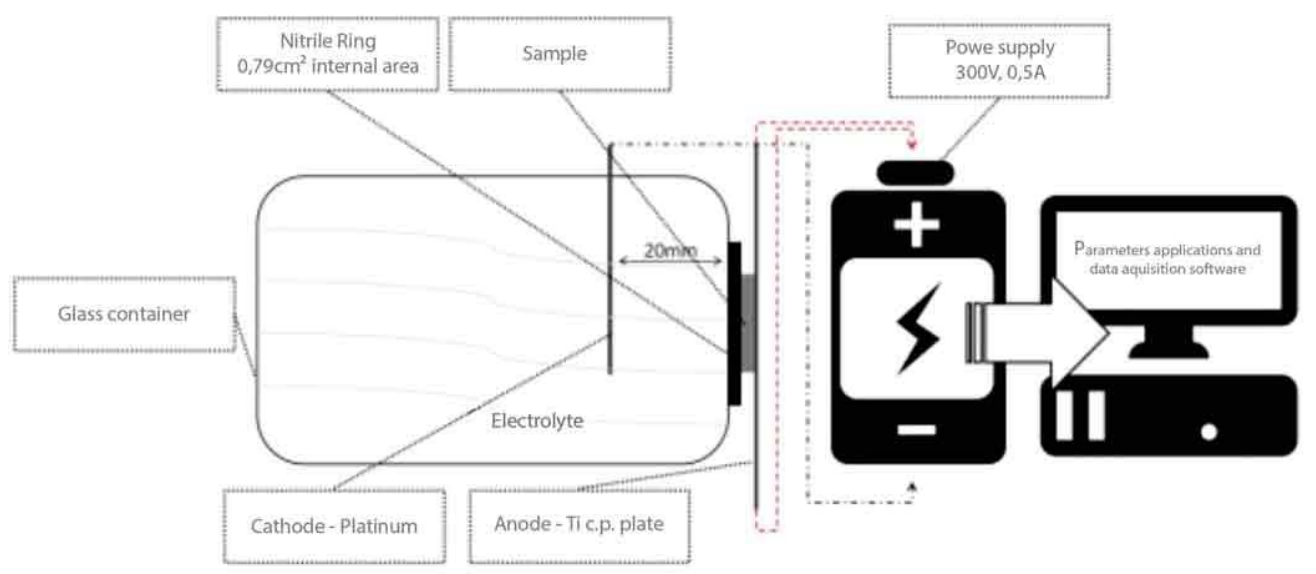

Figure 1: Schematization of the electrolytic cell used for the anodizing process.

\subsection{Methods}

For the development of the anodization process, the sample was fixed with the aid of a nitrile ring, leaving the area of $0.79 \mathrm{~cm}^{2}(1 \mathrm{~cm}$ in diameter) exposed to the electrolyte. The platinum cathode was spiral shaped and positioned parallel to the anode at a distance of $2 \mathrm{~cm}$.

In a preliminary way, electrolyte samples containing $1 \mathrm{M} \mathrm{H}_{3} \mathrm{PO}_{4}$ with $\mathrm{HF}$ concentration variations, at different anodization times and voltages, with or without stirring, were anodized in order to determine the search parameters.

In order to determine the best HF concentration, aiming at the development of nanotubes at room temperature, various acid concentrations were tested, based on the limits established in the literature [23], defined from $0.10 \%$ to $0.40 \% \mathrm{w} / \mathrm{v}$ of $\mathrm{HF}$ in $1 \mathrm{M} \mathrm{H}_{3} \mathrm{PO}_{4}$ solution. Samples were anodized with $20 \mathrm{~V}$ fixed voltage for 30 or 60 minutes, as listed in Table 1.

Table 1: Sample designation and anodizing conditions to determine the optimal $\mathrm{HF}$ concentration on $1 \mathrm{M} \mathrm{H}_{3} \mathrm{PO}_{4}$ electrolyte.

\begin{tabular}{lccc}
\hline SAMPLE & HF [\%] & TIME [MIN] & APPLIED POTENTIAL [V] \\
\hline AM1 Ti-0,1/30 & 0,1 & 30 & 20 \\
AM2 Ti-0,15/30 & 0,15 & 30 & 20 \\
AM3 Ti-0,15/60 & 0,15 & 60 & 20 \\
AM4 Ti-0,16/30 & 0,16 & 30 & 20 \\
AM5 Ti-0,18/30 & 0,18 & 30 & 20 \\
AM6 Ti-0,2/30 & 0,2 & 30 & 20 \\
AM7 Ti-0,22/30 & 0,22 & 30 & 20 \\
AM8 Ti-0,25/30 & 0,25 & 30 & 20 \\
AM9 Ti-0,3/30 & 0,3 & 30 & 20 \\
AM10 Ti-0,3/60 & 0,3 & 60 & 20 \\
AM11 Ti-0,4/60 & 0,4 & 60 & 20 \\
\hline
\end{tabular}

These samples were visualized through scanning electron microscopy (SEM), to verify the best results with respect to producing nanotubes. Thus, according to the results of the samples from Table 1, new samples were obtained by anodization with an electrolyte containing $0.15 \% \mathrm{HF}$, at room temperature, which was not controlled, without and with stirring by magnetic stirrer. These samples are described in Table 2 . 
Table 2: Designation and parameters of samples anodized with $0.15 \% \mathrm{HF}+1 \mathrm{M} \mathrm{H}_{3} \mathrm{PO}_{4}$ electrolyte. S: with stirring. N: No stirring.

\begin{tabular}{|c|c|c|c|c|}
\hline & Samples & $\begin{array}{l}\text { Apllied poten- } \\
\text { tial }(\mathrm{V})\end{array}$ & time $(\min )$ & Stirring \\
\hline \multirow{5}{*}{$\begin{array}{l}S \\
S \\
S\end{array}$} & $1 \mathrm{CA}-\mathrm{Ti}-1 \mathrm{~V}-\mathrm{S}$ & 1 & 30 & Yes \\
\hline & $5 \mathrm{CA}-\mathrm{Ti}-5 \mathrm{~V}-\mathrm{S}$ & 5 & 30 & Yes \\
\hline & 10CA - Ti-10V- & 10 & 30 & Yes \\
\hline & $15 \mathrm{CA}-\mathrm{Ti}-15 \mathrm{~V}-$ & 15 & 30 & Yes \\
\hline & 20CA - Ti-20V- & 20 & 30 & Yes \\
\hline & $1 \mathrm{SA}-\mathrm{Ti}-1 \mathrm{~V}-\mathrm{N}$ & 1 & 30 & No \\
\hline & 5SA - Ti-5V-N & 5 & 30 & No \\
\hline $\mathrm{N}$ & 10SA - Ti-10V- & 10 & 30 & No \\
\hline $\mathrm{N}$ & $15 \mathrm{SA}-\mathrm{Ti}-15 \mathrm{~V}-$ & 15 & 30 & No \\
\hline $\mathrm{N}$ & 20SA - Ti-20V- & 20 & 30 & No \\
\hline
\end{tabular}

The samples described in Table 1 were characterized only for morphology by SEM, while the samples from Table 2 were characterized by the techniques described below.

The surface morphology of titanium oxide films was analyzed by a Scanning Electron Microscope (JEOL), JSM-6510LV, located at the Advanced Studies Laboratory in Materials of the University Feevale; and by a FEI Scanning Electron Microscope with Field Emission Gun (SEM-FEG), model Inspect F50, located in the Central Laboratory of Microscopy and Microanalysis of the Ideia - Research and Development Institute of PUCRS. For both analyzes, the samples were previously prepared with a thin coating of gold by sputtering.

The characterization of the samples was also done by Atomic Force Microscopy (AFM), using a Shimadzu SPM-9500J3 equipment, contact mode, from the Corrosion Research Laboratory (LAPEC) of UFRGS, with the objective of analyzing the surface roughness and morphology. The roughness analyzes developed through AFM were obtained from the parameters $\mathrm{Ra}, \mathrm{Ry}$ and $\mathrm{Rz}$, where Ra, mean roughness, is the arithmetic mean of the absolute values of the roughness profile spacing points in relation to the midline, within the measurement path; Ry, maximum roughness, is the largest value between valleys and peaks on the analyzed measurement path; Rz, total roughness, is the average between the values of valleys and peaks.

The process of dimensional characterization of $\mathrm{TiO} 2$ nanotubes was performed using ImageJ ${ }^{\circledR}$ software. The calibration of the measurements was done by means of the scale indicated in the micrographs and given by the label of the images acquisition software. The diameters of the nanotubes were obtained by means of manual marking with the Scale tool. Sixty measurements were made for each sample.

The wettability of the anodized samples was assessed by a sessile drop test, using SBF (Simulated Body Fluid) as a fluid, using a Krüss goniometer, model DSA30, with Drop Shap Analysis software, owned by LAPEC of UFRGS.

The analysis of the corrosion resistance of non-anodized and anodized samples was done through electrochemical tests using the technique of monitoring the open circuit potential (OCP) and potentiodynamic polarization. In order to carry out these tests, samples of Ti c.p., prepared by mechanical polishing with 280 to 2000 mesh granulating sandpapers, in an electric polisher, and anodized titanium samples were used as work electrodes and were subsequently arranged as follows: (i) Titanium: polished sample without anodic treatment; (II) Nanotubes: sample with porous anodizing to form nanotubes; and (III) Barrier: anodized sample to obtain a barrier layer (in the same conditions of samples (II), with absence of fluoride ions in the electrolyte).

The samples were embedded in epoxy resin in contact with copper wire. All tests were performed using a standard three-electrode cell, and the solution adopted was $1 \%$ (w/v) $\mathrm{NaCl}$.

The electrochemical cell consisted of three electrodes. The work electrodes were prepared with an exposed area of $0.79 \mathrm{~cm} 2$. As a reference electrode, the saturated calomel electrode (SCE) $(\mathrm{Pt}, \mathrm{Hg} / \mathrm{Hg} 2 \mathrm{Cl} 2$ / KClsat) was used. And a platinum electrode was used as the counter electrode.

The equipment used was Autolab PGSTAT 302 Potentiostat. The cathodic and anodic polarization curves were obtained from the open circuit potential (OCP), with a scanning speed of $0.001 \mathrm{~V} / \mathrm{s}$. 


\section{RESULTS AND DISCUSSION}

\subsection{Results of the anodized samples in $1 \mathrm{M} \mathrm{H}_{3} \mathrm{PO}_{4}$ with different $\mathrm{HF}$ concentrations}

Figure 2 shows the morphology of titanium samples anodized in $1 \mathrm{M} \mathrm{H}_{3} \mathrm{PO}_{4}$ with various $\mathrm{HF}$ concentrations, according to Table 1 .
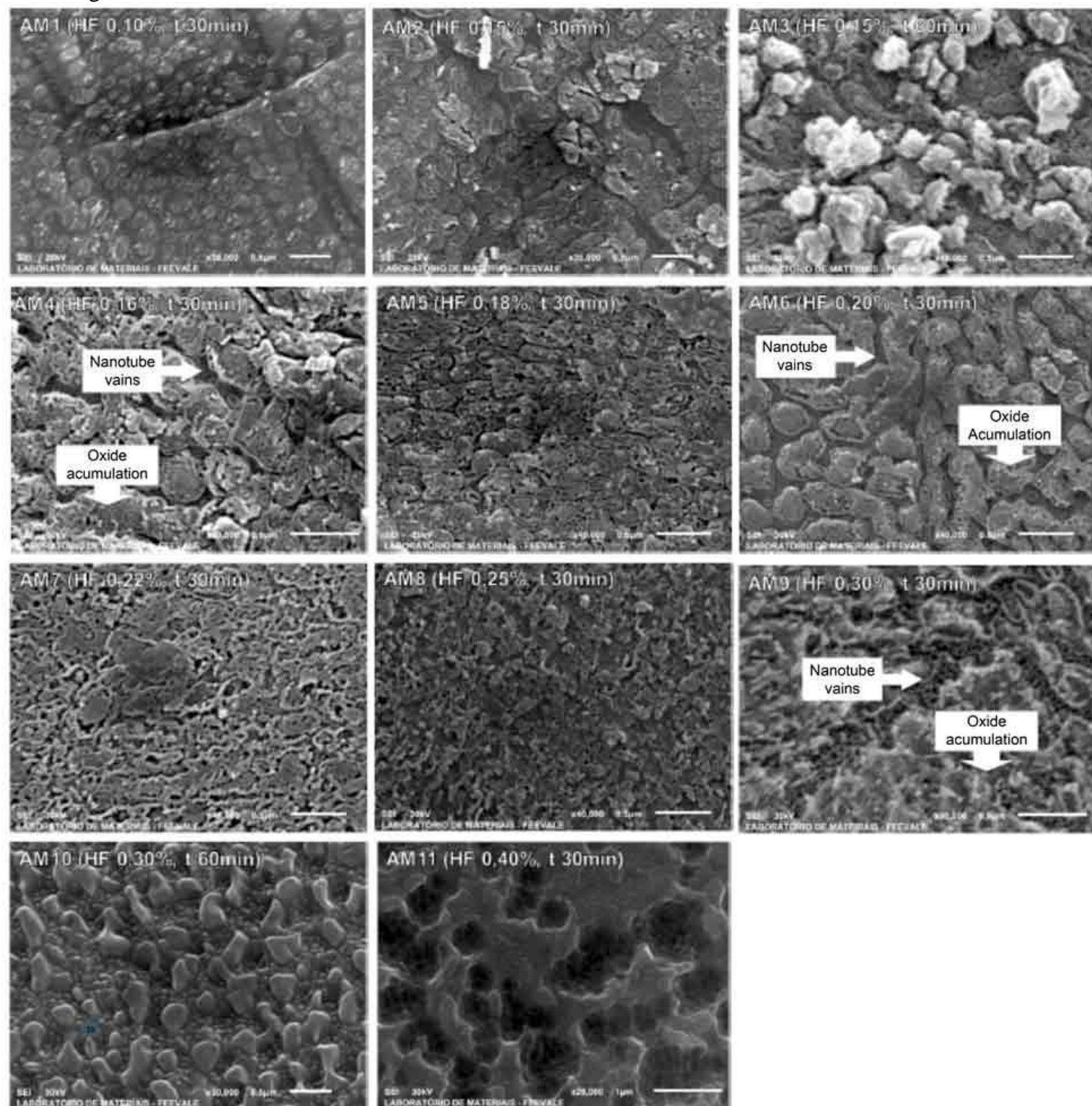

Figure 2: Morphology of anodized samples at $20 \mathrm{~V}$, without stirring, under various conditions of HF concentration and anodizing (AM1 and AM11).

It is observed that the anodized sample in $0.10 \% \mathrm{w} / \mathrm{v}$ HF presented an irregular morphology, containing pores that approach nanotubes that are not well-defined. Increasing HF concentration $(0.15 \% \mathrm{w} / \mathrm{v})$, the tubes seem to be better defined. However, at concentrations higher than $0.15 \% \mathrm{HF}$, there is an accumulation of oxide material on the surface of the formed nanotubes. The micrographs show that the formation of hydroxides on the surface is favored, which entails the coating of the lower layer, in which the nanotubes were growing. As a consequence, the samples presented the appearance of regions of "veins-shaped" nanotubes, located under cracks in the accumulated oxide layer, as identified in AM4, AM6 and AM9 samples (Figure 2).

The literature reports the appearance of agglomerates grown on the oxide formed in the presence of $\mathrm{H}_{3} \mathrm{PO}_{4}$ electrolyte, which are explained by the long oxidation time. Firstly, the oxide homogeneously grows up to a limit thickness (determined by the applied potential), but when exposed to a high oxidation time, the clusters appear [24]. The magnetic stirring mechanism can mitigate the formation of superficial clusters, ensuring that the ions diffusion into the electrolyte is homogeneous.

According to the obtained results, it was decided to anodize in conditions of lower HF concentration, 
of $0.15 \%$.

\subsection{Results of the anodized samples in $1 \mathrm{M} \mathrm{H}_{3} \mathrm{PO}_{4}+0.15 \% \mathrm{HF}$}

It is observed that the anodized samples morphology at $10 \mathrm{~V}$ and $20 \mathrm{~V}$, without stirring, presents nanotubes on the oxides surface, being the best results obtained among all the samples. In addition, Figure 3 shows the variation in pore size formed at $10 \mathrm{~V}$ and $20 \mathrm{~V}$, which range from $100 \mathrm{~nm}$ (external diameter) to 50 $\mathrm{nm}$ (internal diameter). None of the other samples presented the formation of surface nanotubes, therefore, it was considered unnecessary to present the morphology of the other samples.

From the results, it was identified that the best voltage parameter to be used in a standardized way in the samples to be submitted to the validation tests was $10 \mathrm{~V}$, due to the better quality of the obtained nanotubes, as well as the reduced diameter, within the expected range of $15 \mathrm{~nm}^{25}$. In addition, it was opted for anodization without stirring, since the presence of nanotubes was only identified in this case.

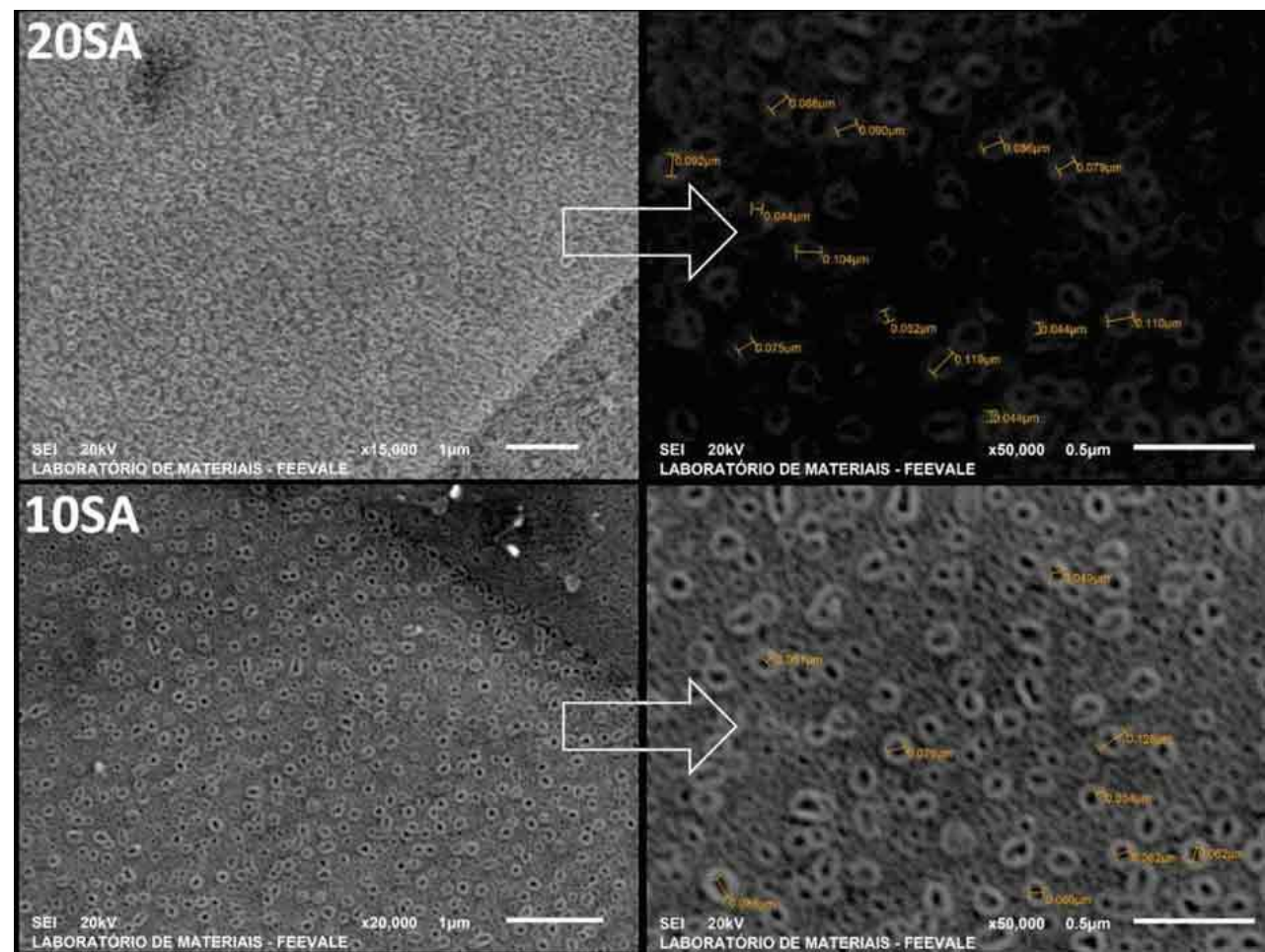

Figure 3: Morphology of the anodized samples for $30 \mathrm{~min}$, without stirring in electrolyte containing $0.15 \%$ of $\mathrm{HF}$ under the following conditions: 20SA-20V and 10SA-10V.

\subsection{Results of the anodized samples in $1 \mathrm{M} \mathrm{H}_{3} \mathrm{PO}_{4}+\mathbf{0 . 1 5 \%} \mathrm{HF}$, at $10 \mathrm{~V}$, for $\mathbf{3 0}$ min, without stirring}

Once the standard anodizing conditions for obtaining nanotubes were determined in a systematic way, for the purposes of validation, new samples were anodized under the same critical pre-determined conditions: electrolyte containing $1 \mathrm{M} \mathrm{H}_{3} \mathrm{PO}_{4}+0.15 \% \mathrm{HF}$, application of $10 \mathrm{~V}$ for 30 minutes without stirring. Therefore, the following results will relate to these samples.

Figure 4 shows the potential and current density transients of the anodized samples. As the anodizing curve is stable over time, it was chosen to show only the first 100 seconds of the total time of 30 min, with the first seconds being the most representative of the process.

In the transients of Figure 4 (voltage $\mathrm{x}$ time) there is a rather abrupt potential growth, which stabilizes at $10 \mathrm{~V}$. It is known that the growth of the oxide is related to the potential increase that, in this case, indicates the formation of an oxide of very thin thickness [26-28]. On the other hand, it should be considered that the current obtained after the potential achieves $10 \mathrm{~V}$ is practically zero, indicating the formation of barrier oxide, which was not observed in this work. It was expected, therefore, due to the formation of nanotubes, that the final current (after the potential reaches $10 \mathrm{~V}$ ) was not zero, since it is responsible for forming attack points distributed on the area relative to the pores. In this case, because the diameter of the nanotubes is very small, the oxide behaves as a barrier, with a uniform current distribution on its surface, leading to its drop to a practically null value. Thus, the addition of HF to the electrolyte would be the most impacting factor in the formation of nanotubes. 

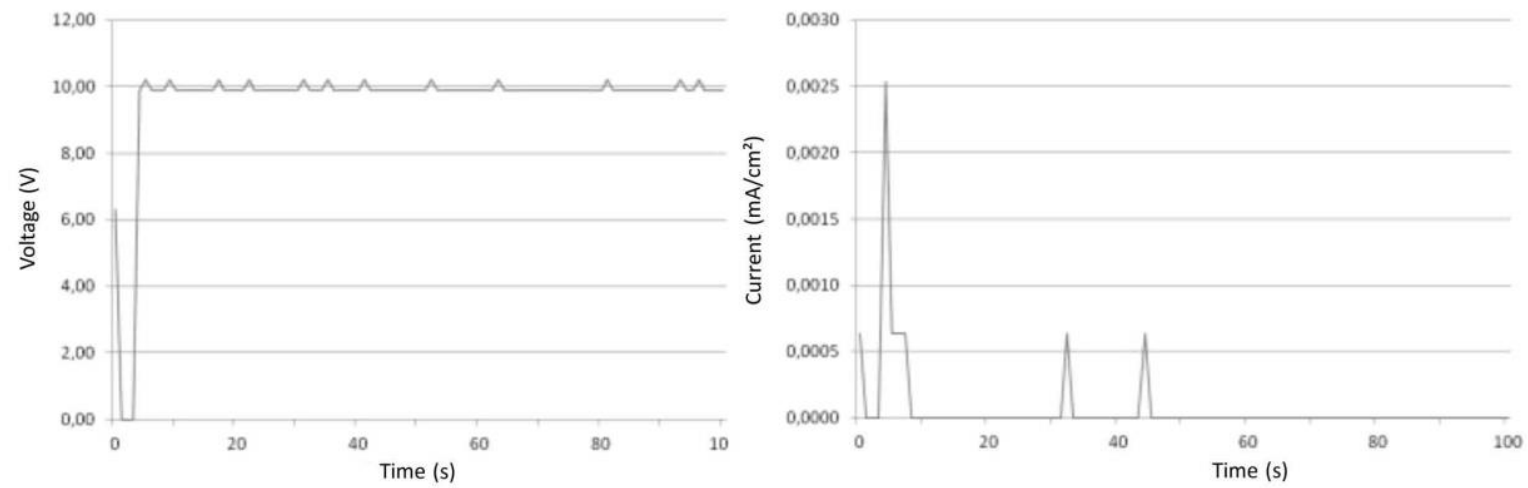

Figure 4: Potential transients and current density of the anodized samples to obtain nanotubes for the $0 \mathrm{~s}-100 \mathrm{~s}$ range of the anodizing process.

Figure 5 shows the micrographs obtained by a) SEM-FEG and b) AFM of the anodized sample under the conditions previously defined to obtain nanotubes, $1 \mathrm{M} \mathrm{H}_{3} \mathrm{PO}_{4}+0,15 \% \mathrm{HF}$, at $10 \mathrm{~V}$, for $30 \mathrm{~min}$. It is observed structures of nanotubular shape, suggesting the stability of the process and the parameters determined in the experimental stage. In addition, the growth of nanotubes in the grain contours is clearly observed, which agrees with the results of the anodizing curves, in which the oxide formed is quite thin, since the nanotubes growth is not enough to cover the grain, being possible to identify its grain boundary (Figure 5a). This suggests that the size of the nanotubes is at the order of nanometers, and its diameter is equally small, confirming the values previously obtained for the dimensions.
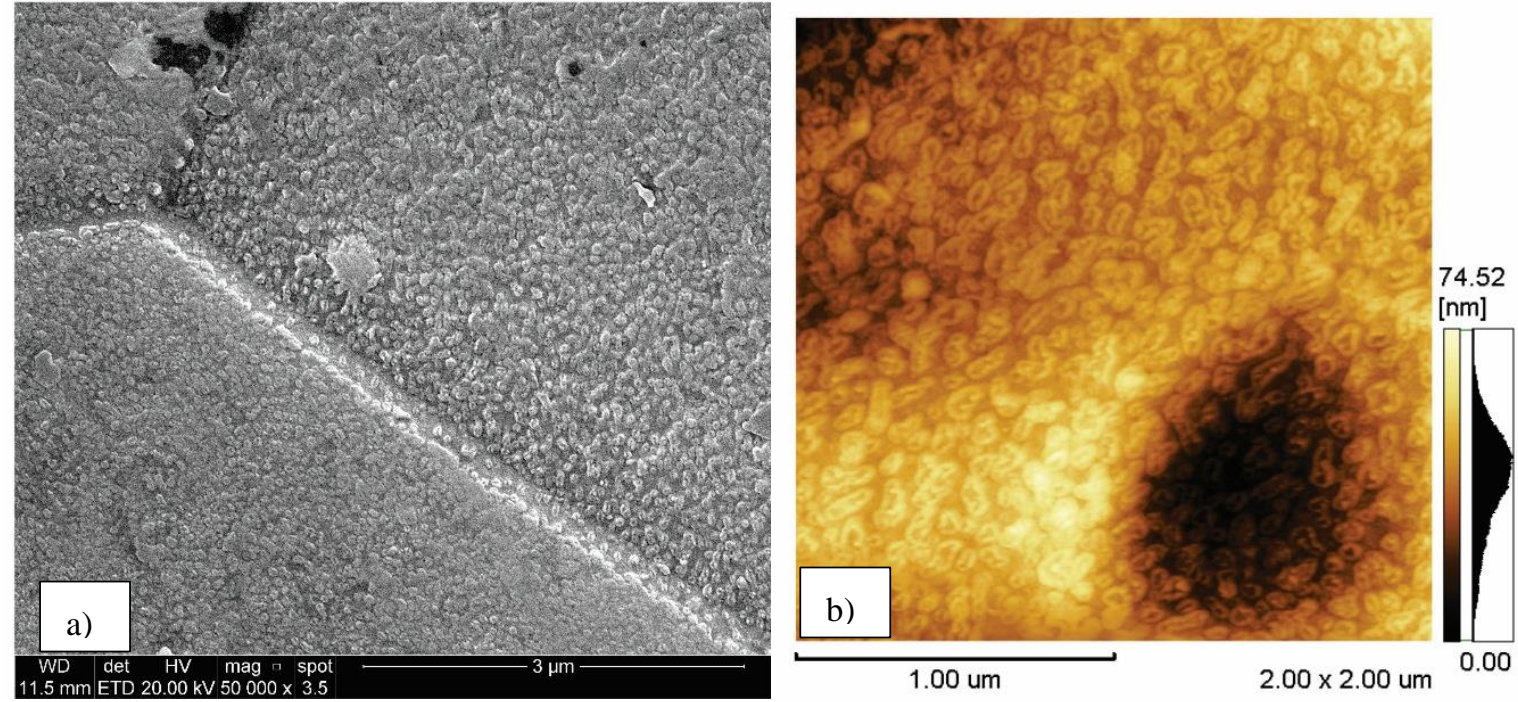

Figure 5: Morphology of anodized titanium in $1 \mathrm{M} \mathrm{H}_{3} \mathrm{PO}_{4}+0.15 \% \mathrm{HF}$, at $10 \mathrm{~V}$, for 30 min by a) SEM-FEG and b) AFM.

With the aid of ImageJ® software, the nanotubes were measured in anodized samples according to the SEM-FEG images, and 60 diameter measurements of the samples were made. The data were treated statistically, obtaining the average diameter of the nanotubes, the dispersion of the measurements by standard deviation and maximum and minimum diameter values by sample.

The mean diameter obtained in the samples ranged from $61 \mathrm{~nm}$ to $76 \mathrm{~nm} \pm 10 \mathrm{~nm}$, approaching the mean diameter of $50 \mathrm{~nm}$ obtained by Park et al. for the same anodizing potential $(10 \mathrm{~V})$. However, the standard deviation of the measurements of the analyzed samples in this study is much higher than the one verified in the study of the mentioned author. The mean diameter of the tubes was penalized by the low homogeneity in the diameter of the dispersed nanotubes, and the smaller diameter nanotubes have lower visibility due to the limitation of the characterization methods. The obtained nanotubes have mean diameter outside the zone considered optimal by Park et al. for the cellular response optimization in the anodizing process.

The anodized samples were submitted to morphological and roughness characterization by Atomic Force Microscopy (AFM), and the results obtained are shown in Figure 5b. 
The roughness analysis was performed in triplicate on $2 \mu \mathrm{m} \times 2 \mu \mathrm{m}$ images, seeking a better definition of the nanotubes. The mean parameters obtained for $\mathrm{Ra}=7.848 \mathrm{~nm}, \mathrm{Ry}=68.764 \mathrm{~nm}$ and $\mathrm{Rz}=33.547 \mathrm{~nm}$.

It is observed in Figure $5 b$ the formation of nanotubular structures on the sample with roughness average of approximately $8 \mathrm{~nm}$ and with peaks of $70 \mathrm{~nm}$. The literature indicates that nanotubes formed by first generation processes (electrolyte containing HF) have a maximum thickness limited to $1 \mu \mathrm{m}$, so the samples with smaller roughness, as obtained, were already expected [29].

The anodized samples in the nanotube condition were subjected to wettability tests through sessile drop method with a goniometer, and the results were demonstrated in different regions of the samples, according to Figure 6.

Regarding the surface wettability, it is possible to affirm that the conditions of anodization to obtain. nanotubes is indicated as superficial treatment in implants. The low mean surface contact angle with the SBF drop $\left(\theta \mathrm{c}<90^{\circ}\right)$, presented by all the samples in all analyzed areas, shows that after implantation the nanostructured surface can increase the interaction between the body fluid and the biomaterial, due to the hydrophilic behavior shown [30].

Contact angle: $56,9^{\circ}$

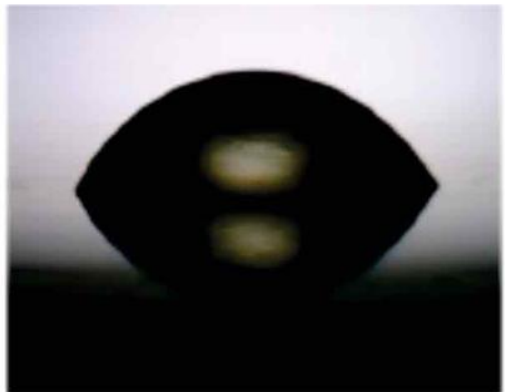

Contact angle: $63,5^{\circ}$

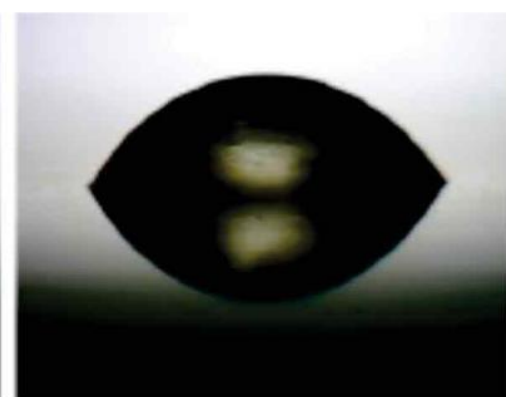

Contact angle: $58,5^{\circ}$

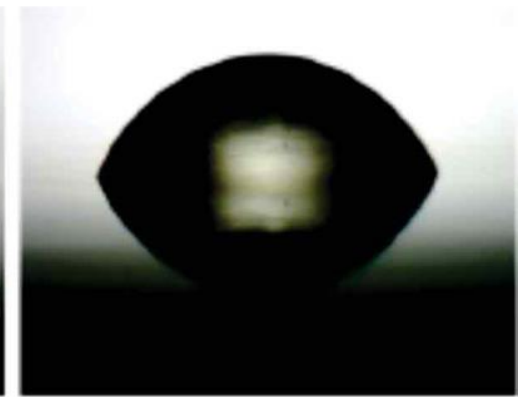

Figure 6: Contact angle image on three different areas of the anodized sample.

The potentiodynamic polarization tests were performed comparatively between three types of samples: (I) Titanium: polished sample without anodic treatment; (II) Nanotubes: anodized sample containing nanotubes; and (III) Barrier: anodized sample to obtain a barrier layer (under the same conditions as samples (II), with absence of fluoride ions in the electrolyte).

The analyzes were performed on electrolyte containing $1 \% \mathrm{NaCl}$ solution $(\mathrm{w} / \mathrm{v})$, and the polarization curves are shown in Figure 7, respectively.

Figure 7 shows a displacement of the corrosion potential of the sample containing nanotubes, followed by the sample with barrier oxide, compared to Ti c.p. This behavior was already expected since these samples contain oxides thicker than those naturally formed in the air, being therefore more stable [31]. On the other hand, the sample containing nanotubes, although presenting a nobler potential compared to Ti c.p., is less noble than the barrier titanium oxide. As the nanotube layer is very thin, possibly thinner than the formed barrier oxide (since the titanium has a growth rate of $2 \mathrm{~nm} / \mathrm{V}$ ), it is assumed that the formed barrier oxide has a thickness greater than the size of the nanotubes [32]. In addition, it should be considered that the barrier layer is continuous and has no pores, such as that of the nanotubes, which would explain the nobler behavior of this sample. On the other hand, it is observed that the corrosion limit current also decreases with the displacement of the potential to more positive values, which indicates the more protective character of the barrier sample. However, it is still worth noting that nanotubes exhibit nobler behavior compared to Ti c.p. 


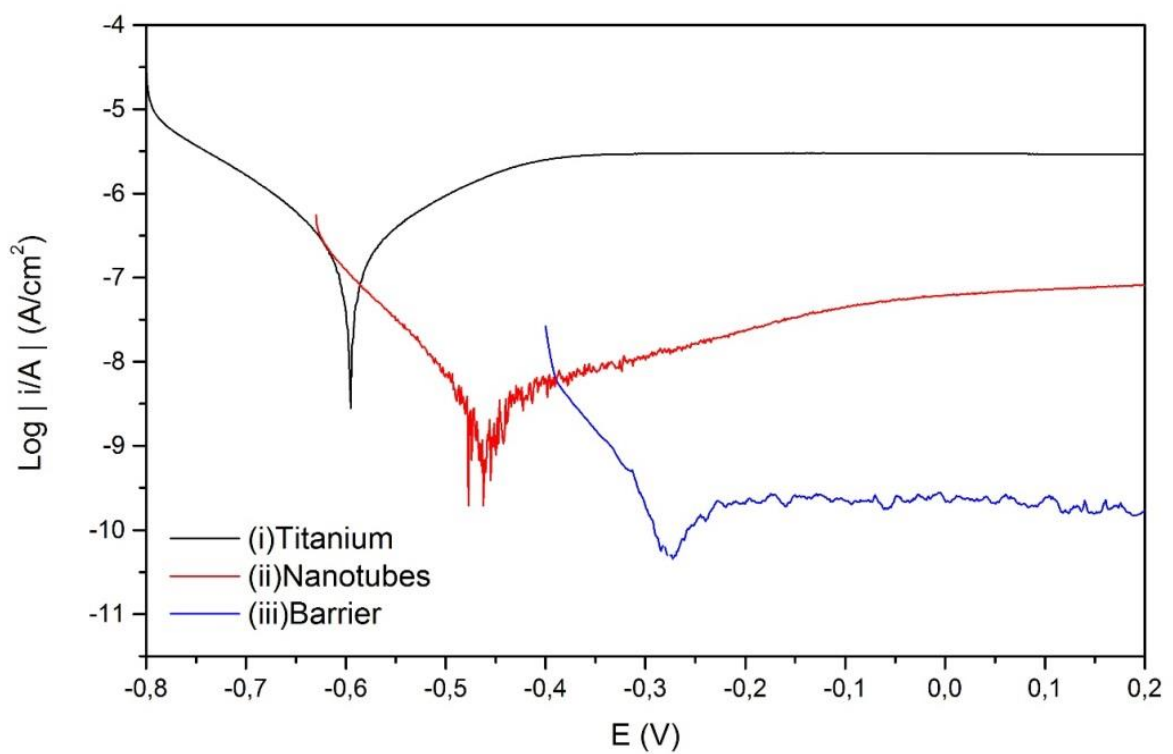

Figure 7: Polarization curves of Ti c.p. samples (i) non-anodized, (ii) with nanotubes and (iii) with barrier anodization in $1 \%(\mathrm{w} / \mathrm{v}) \mathrm{NaCl}$ solution.

\section{CONCLUSIONS}

Obtaining the nanotubes using the anodic technique with $\mathrm{H}_{3} \mathrm{PO}_{4}$ electrolyte in the presence of $0.15 \% \mathrm{HF}$, under potentiostatic mode, $10 \mathrm{~V}$, for $30 \mathrm{~min}$, in a rectifier source, is feasible, reproducible and low cost.

The morphological analysis by SEM-FEG and AFM was successful, being possible to verify that the pore diameter is close to the one found in the literature for the same potential, but heterogeneous. The roughness of the samples shows that the film of formed nanotubes is thin, but the literature indicates that the thickness is not as relevant as the nanotubes morphology and diameter, when it comes to the performance of nanostructures as osseointegration process optimizers.

The performance in the wettability test still indicates that the material has a hydrophilic surface, a characteristic desired to optimize material performance in the osseointegration process.

The performance of the samples in the potentiodynamic polarization tests demonstrates that the material with nanostructured coating exhibits high corrosion resistance in saline $(1 \% \mathrm{NaCl})$, proving to be a safe material for implantation. Thus, it is concluded that the described process is efficient in the development of surfaces of titanium oxide nanotubes, with morphological, corrosion resistance and hydrophilic characteristics that would indicate its use as an implantable material.

\section{ACKNOWLEDGMENTS}

The authors would like to acknowledge the financial support of CNPq and CAPES.

\section{BIBLIOGRAPHY}

[1] PETERS, M., LEYENS, C. "Titanium and Titanium Alloys: Properties and Selection Nonferrous Alloys and Special Purpose Materials", ASM Handbook, v. 2, 2003.

[2] RENZ, R.P. "Osseointegration evaluation of treated surfaces of titanium implants applying tensile pull out test”, Journal of Dental Clinics and Research, v. 3, pp. 149-157, 2007.

[3] CUNHA, A., et al. "A surgical procedure using sheep as an animal model to evaluate osseointegration", Journal of Dental Clinics and Research, v. 3, pp. 59-62, 2007.

[4] ROBERTSON, D.S. "The relationship of physical and chemical processes in bone and blood formation", Medical Hypotheses, v. 61, pp. 623-635, 2010.

[5] LEE, W.J. "Oxide nanotube arrays fabricated by anodizing processes for advanced material application", Current Applied Physics, v. 8, pp. 818-821, 2008.

[6] GEETHA, M. "Ti based biomaterials, the ultimate choice for orthopaedic implants". Progress in Materials Science, v. 54, pp. 397-425, 2009. 
[7] LIU, X. et al. "Surface modification of titanium alloys, and related materials for biomedical applications". Materials Science and Engineering, v. 47, pp. 49-121, 2004.

[8] HANAWA, T.A. "Comprehensive review of techniques for biofunctionalization of titanium". Journal of Periodontal \& Implant Science, v. 41, pp. 263-272, 2011.

[9] KOKUBO, K., MATSUSHITA, T., TAKADAMA, H. et al.,"Development of bioative materials on surface chemistry", Journal of the European Ceramic Society, v. 29, pp. 1267-1274, 2009.

[10] MINAGAR, S. et al. "A review of the application of anodization for the fabrication of nanotubes on metal implant surfaces", Acta biomaterialia, vol. 8, pp. 2875-88, 2012.

[11] FADL-ALLAH, S.A., MOHSEN, Q.. "Characterization of native and anodic oxide films formed on commercial pure Ti using electrochemical properties and morphology techniques", Applied Surface Science, v. 256, pp. 5849-5855, 2010.

[12] RYAN, G., et al. "Fabrication methods of porous metals for use in orthopaedic applictions", Biomaterials, v. 27, pp. 2651-2670, 2006.

[13] GUEHENNEC, L., SOUEIDAN, A., LAYROLLE, P., et al., "Surface treatments of titanium dental implants for rapid osseointegration", Dental Materials, v. 23, pp. 844-854, 2007.

[14] KIM, S.E., LIM, J.H., LEE, S.C., et al., "Anodically nanostructured titanium oxides for implant applications", Electrochimica Acta, v. 53, pp. 4846-4851, 2008.

[15] VARIOLA, F., BRUNSKI, J.B., ORSINI, G. et al., "Nanoscale surface modifications of medically relevant metals: State-of-the art and perspectives", Nanoscale, v. 3, pp. 335-353, 2011.

[16] BRESSAN, E., SBRICOLI, L., GUAZZO, R. et al., "Nanostructured surfaces of dental implants", International Journal of Molecular Science, v. 14, pp. 1918-1931, 2013.

[17] ADAMEK, G., JAKUBOWICZ, J. "Mechanoelectrochemical synthesis and properties of porous nanoTi-6Al-4V alloy with hydroxyapatite layer for biomedical applications", Electrochemistry Communications, v. 12, pp. 653-656, 2010.

[18] DIAMANTI, M.V., PEDEFERRI, M.P. "Effect of anodic oxidation parameters on the titanium oxides formation”, Corrosion Science, vol. 49, pp. 939-948, 2007.

[19] MA, Q. et al. "Enhancement of the bioactivity of titanium oxide nanotubes by precalcification", Materials Letters, vol. 62, pp. 3035-3038, 2008.

[20] CUI, C.X., et al., "Microstructure and antibacterial property of in situ $\mathrm{TiO}(2)$ nanotube layers/titanium biocomposites", Journal of the mechanical behavior of biomedical materials, v. 8, pp. 178-183, 2012.

[21] LORENZ, K., et al. "Anodic $\mathrm{TiO}_{2}$ nanotube layers electrochemically filled with $\mathrm{MoO}_{3}$ and their antimicrobial properties", Biointerphases, v. 16-21, 2011.

[22] CUI, X., KIM, H.M., KAWASHITA, M. et al.,"Preparation of bioactive titania films on titanium metal via anodic oxidation", Dental Materials, v. 25, pp. 80-86, 2009.

[23] ROY, P., BERGER, S., SCHMUKI, P.. "TiO ${ }_{2}$ nanotubes: synthesis and applications", Angewandte Chemie International Edition, v. 50, pp. 39-2904, 2011.

[24] RAJA, K.S., MISRA, M., PARAMGURU, K.. "Formation of self-ordered nano-tubular structure of anodic oxide layer on titanium". Electrochimica Acta, v. 51, pp. 154-165, 2005.

[25] BAUER, S., PARK, J., FALTENBACHER, J. et al.,"Size selective behavior of mesenchimal stem cells on $\mathrm{ZrO}_{2}$ and $\mathrm{TiO}_{2}$ nanotube arrays", Integrative Biolpgy. (Camb.), v. 1, pp. 32-525, 2009.

[26] DIAMANTI, M.V., PEDEFERRI, M.P.. "Effect of anodic oxidation parameters on the titanium oxides formation". Corrosion Science, v. 49, pp. 939-948, 2007.

[27] LIU, Z., et al. "Characterization of anodic oxide growth on commercially pure titanium in NaTESi electrolyte", Surface and Coatings Technology, v. 1025-1031, 2014.

[28] KOCIUBCZYK, A.I., et al. " $\mathrm{TiO}_{2}$ Coatings in Alkaline Electrolytes Using Anodic Oxidation Technique", Procedia Materials Science, v. 8, pp. 65-72, 2015.

[29] MACAK, J., TSUCHIYA, H., GHICOV, A.. " $\mathrm{TiO}_{2}$ nanotubes: self-organized electrochemical formation, properties and applications”, Solid State and Materials Science, v. 11, pp. 3-18, 2007.

[30] INDIRA, K., MUDALI, U.K., RAJENDRAN, N. "Corrosion behavior of electrochemically assembled nanoporous titania for biomedical applications", Ceramics International, v. 39, pp. 959-967, 2013. 
[31] LORENZETTI, M., PELLICER, E., SORT, J. et al., "Improvement to the Corrosion Resistance of TiBased Implants Using Hydrothermally Synthesized Nanostructured Anatase Coatings", Material, v. 7, pp. 180-194, 2014.

[32] KOWALSKI, D., DOOHUN, K., SCHMUKI, P. " $\mathrm{TiO}_{2}$ nanotubes, nanochannels and mesosponge: Selforganized formation and applications", NanoToday, v. 8, pp. 235-264, 2013.

\section{ORCID}

Sandra Raquel Kunst

http://orcid.org/0000-0002-8060-3981

Thaís Francine Graef

https://orcid.org/0000-0002-8259-4222

Luã Tainachi Mueller

https://orcid.org/0000-0001-5920-9691

Fernando Dal Pont Morisso

https://orcid.org/0000-0002-9653-9857

Carlos Leonardo Pandolfo Carone

https://orcid.org/0000-0002-4084-4502

Luciane Taís Fuhr

Cláudia Trindade Oliveira

Jane Zoppas Ferreira

https://orcid.org/0000-0001-8053-3613

https://orcid.org/0000-0002-4472-5359

https://orcid.org/0000-0002-3137-297X 